\title{
Spatial Variation of Seismicity in Central Himalayan Region
}

\author{
Bhesha Raj Adhikari' and H. Paudyal ${ }^{2}$ \\ ${ }^{1}$ Bhaktapur Multiple Campus, Bhaktapur and ${ }^{2}$ Birendra Multiple Campus, Bharatpur \\ E-mail:- b.r.adhikari@hotmail.com
}

\begin{abstract}
Spatial variation of seismicity in Central Himalayan Region for the period 1964 to 2008 has been studied. Seismic activity is highly concentrated in western Nepal, fairly scattered in central Nepal and concentrated in south-eastern Nepal where the activity offset towards North from major faults.
\end{abstract}

Keywords: Tectonic features, MCT and MBT, Criss-cross Pattern, Seismic Activity

\section{INTRODUCTION}

High seismic activity in the Himalayan region is reflected by the frequency of earthquakes of large, medium and small magnitudes in this region since the historical past (Oldham, 1882; Gutenberg and Richter, 1954; Chandra, 1992). The cause of earthquakes in this region is due to relatively high stress buildup by the continual convergence of the Indian and Eurasian plates where the Indian plate slides beneath the Himalaya along a shallow plane causing some internal deformation of the overlying mountains. Nepal, located in the central part of the Himalayan region, has been sites of several large earthquakes including one great earthquake (1934, M 8.4) during the last century. This region exhibits all major tectonic features of the Himalayan compression zone.

An earthquake catalogue covering wide range magnitude is required to understand characteristics of seismic activity, and such database is lacking for Nepal and its adjoining region. In view of the above facts, in the present study, a seismicity database for the considered region for the last 45 years (19642008) has been compiled by considering all the available earthquake catalogues. The region is under high degree of seismic risk that may cause a huge loss of lives and property in future earthquake (Wyss, 2005). Hence, the study of seismic activity may be important since it plays a vital role in understanding the current status of geodynamic phenomena in the region.

\section{EARTHQUAKE DATA}

In this study Nepal and its adjoining region in a $9^{\circ}$ $x 5^{\circ}$ space window (bounded by $80.0^{\circ} \mathrm{E}$ to $89.0^{\circ} \mathrm{E}$ Longitude and $26.0^{\circ} \mathrm{N}$ to $31.0^{\circ} \mathrm{E}$ Latitude) is considered for study spatial variation of seismicity by using updated and complete seismicity database. The final database contains 1141 earthquakes comprising 3 and 12 events having magnitude range $\mathrm{m}_{\mathrm{b}} 6.5$ - 6.7 and greater than 6.0 respectively. The data base contains 524, 109 and 20 events in magnitude range $4.1-4.9,5.0-5.4,5.5-5.9$ respectively and rests (216 events) are without magnitude. Using completeness check, cutoff magnitude is computed as $m_{b}=4.1$.

Earthquake frequency magnitude relationship is a way to examine the seismic activity in an area. The b-values represent the different types of seismic activity in different seismotectonic environment; it may be related to the properties of the medium and the prevailing stress condition in the localities. The $b$ - value describes the ratio of occurrence of small to large earthquakes, and its global value is $\sim 1$, meaning a 10 -fold decrease in seismic activity associated with the subsequent increase of one unit in magnitude. The $b$ value has been estimated using the most widely used empirical relation between magnitudes and frequency of earthquake occurrence in a region given by Gutenberg and Richter (1944)

$$
\log N=\mathrm{a}-\mathrm{b} M
$$

where $N$ represents the number of earthquakes of magnitude $M$ or greater than $M$ per unit time, a and $\mathrm{b}$ are constants for a given region representing seismic character. 
Using the seismic data for the aforementioned period, the relation established for the Central Himalayan Nepal region (Fig. 3) is

$$
\log N=7.29-1.05 \text { m with } \mathrm{R}^{2}=0.99 \text {. }
$$

The curve fits best for data with magnitude 4.1 and above (with regression coefficient $\mathrm{R}^{2}=0.99$ ), which represents the cut-off magnitude is 4.1 for the study area and $b-$ value is estimated to be 1.05 .

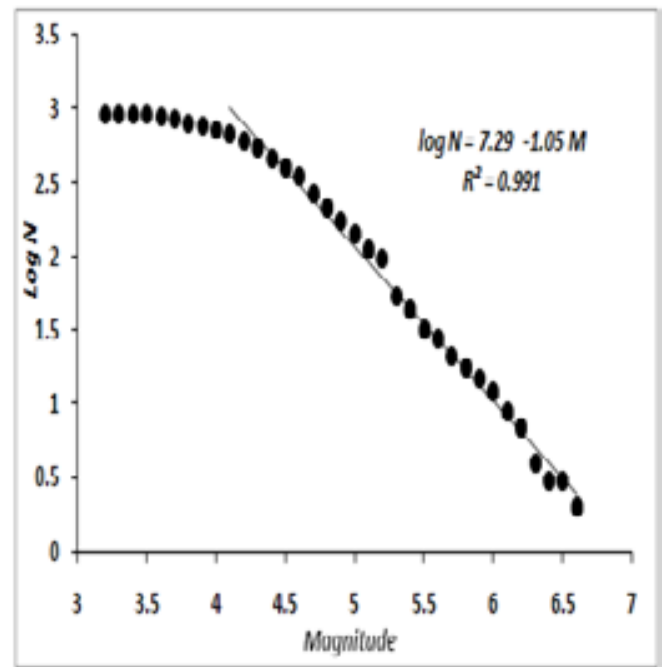

Figure 1: b-value estimates for Central Himalayan region using earthquake data from 1964-2008

The final database comprises a total of 665 events occurred in the region with cutoff magnitude $\mathrm{m}_{\mathrm{b}}=$ 4.1. Rest 476 events are lies in the incomplete part of the catalog. In the present study, the complete database has been analyzed.

\section{ANALYSIS OF DATA}

The spatial pattern of events with $m_{b} \geq 4.1$ is dipictded in Figure 2. The activity is very high in the Himalayan arc. It is highly concentrated in western Nepal fairly scattered in central Nepal and again concentrated in south-eastern Nepal. In the Tibetan side to in the north of Higher Himalaya packet of intense activity occurred in $83^{\circ}-84^{\circ} \mathrm{E}$ and $30^{\circ}$ $-31^{\circ} \mathrm{N}$ and in and around $88^{\circ} \mathrm{E}$ and $30^{\circ} \mathrm{N}$. The region bounded by $82.5^{\circ}-87.5^{\circ} \mathrm{E}$ and $29^{\circ}-30^{\circ} \mathrm{N}$ exhibits low seismic activity however few scattered events are observed. It clearly shows that the region between $80^{\circ}-84^{\circ} \mathrm{E}$ and $26^{\circ}-28^{\circ} \mathrm{N}$ is seismically quiescent.

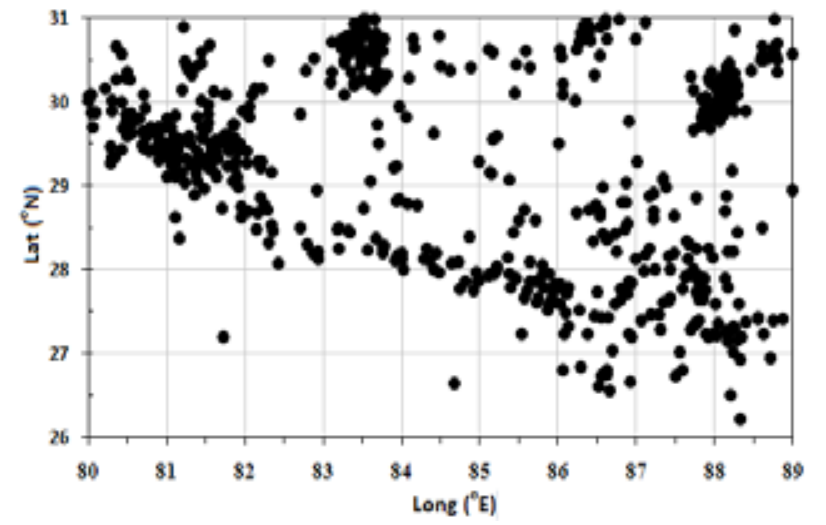

Figure 2: Spatial distribution of earthquakes in Nepal and its adjoining region for the period 1964-2008 with $\mathrm{m}_{\mathrm{b}} \geq$ 4.1 ( 665 events).

In order to study the seismicity characteristic in detail, the study area is divided into three smaller segments based on spatial distribution of events and its correlation with tectonic features. The delineation of regions is as follows:

Region A: Western Nepal and its adjoining region $\left(80.0^{\circ} \mathrm{E}\right.$ to $82.5^{\circ} \mathrm{E} ; 26.0^{\circ} \mathrm{N}$ to $31.0^{\circ} \mathrm{E}$ )

Region B: Central Nepal and its adjoining region $\left(82.5^{\circ} \mathrm{E}\right.$ to $85.5^{\circ} \mathrm{E} ; 26.0^{\circ} \mathrm{N}$ to $31.0^{\circ} \mathrm{E}$ )

Region C: Eastern Nepal and its adjoining region $\left(85.5^{\circ} \mathrm{E}\right.$ to $89.0^{\circ} \mathrm{E} ; 26.0^{\circ} \mathrm{N}$ to $31.0^{\circ} \mathrm{E}$ )

The frequency of the earthquakes in three delineated regions with respect to magnitude is depicted in Table 1. It shows that the annual frequencies in these regions are 4, 3.5 and 7 respectively.

Table 1: Frequency of earthquakes that have been occurred from 1964-2008 in three delineated regions in Central Himalayas with respect to magnitude.

\begin{tabular}{|l|c|c|c|c|}
\hline \multirow{3}{*}{$\begin{array}{l}\text { Delineated } \\
\text { Regions }\end{array}$} & \multicolumn{5}{|c|}{ Mumber of earthquakes } \\
\cline { 2 - 5 } & $\geq 4.1$ & $\geq 5.0$ & $\geq 5.5$ & $\geq 6.0$ \\
\cline { 2 - 5 } $\begin{array}{l}\text { Central } \\
\text { Himalaya }\end{array}$ & 665 & 141 & 32 & 12 \\
\hline Region A & 186 & 53 & 13 & 4 \\
\hline Region B & 165 & 32 & 7 & 4 \\
\hline Region C & 314 & 56 & 12 & 4 \\
\hline
\end{tabular}

In region $\mathrm{A}$, major thrusts and some northeastsouthwest trending transverse faults (such as Tanakpur, Karnali, Samea) are the main tectonic 
features causing the seismic activity in the region. Since 1964 to 2008, a total of 273 events have occurred which include $68 \%$ with $\mathrm{m}_{\mathrm{b}} \geq 4.1 ; 19 \%$ with $\mathrm{m}_{\mathrm{b}} \geq 5$. The spatial distribution of these earthquakes is shown in Fig.3. The majority of shallow and intermediate events are located between the MCT and the MBT, and also along and in between the transverse faults which indicate there may be a combined role in triggering these earthquakes. Most of the intermediate events are observed between the MCT and the MBT in the central portion. Four medium size earthquakes with $\mathrm{m}_{\mathrm{b}} \geq 6$ have occurred in the region from 1964 to 2008 in Far-Western Nepal near to the Indian region. These earthquakes appear to be associated with the MCT and the MBT. Bajhang earthquake of 1980 is the recent major earthquake which caused severe damages and casualties. Annual frequency of events is more than 4 having magnitude $\geq 4.1$. The seismicity in the westernmost part around $80^{\circ} \mathrm{E}$ appears to be associated with the MCT. A large area bounded by $29^{\circ}-30^{\circ} \mathrm{N}$, shows several clusters of events, which are probably related with the existing transverse faults. Nearly no seismic activity is observed to the south of $28^{\circ} \mathrm{N}$.

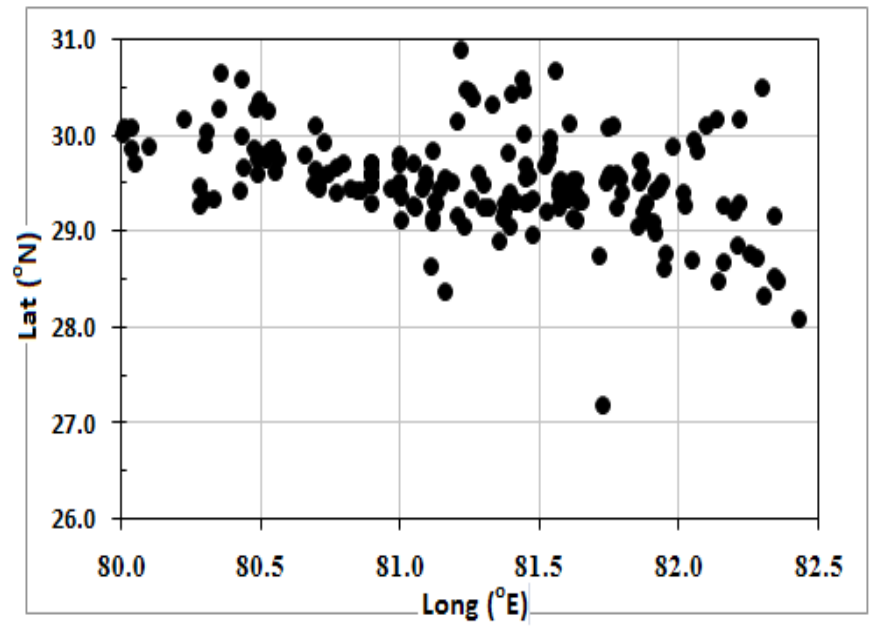

Figure 3: Spatial distribution of earthquakes in Western Nepal and its adjoining region from 1964 to $2008\left(\mathrm{~m}_{\mathrm{b}} \geq 4.1\right)$.

The major tectonic features in Central Nepal and its adjoining areas of Tibet and India are the MCT, MBT, MFT, the several transverse faults striking across the Himalaya and the almost northsouth and northeast-southwest trending normal faults/grabens. The MCT bends southward sharply at about $85^{\circ} \mathrm{E}$ followed by its westward extension for about $50 \mathrm{~km}$. Here, the MCT meanders and comes close to the MBT and follows its usual eastward trend parallel to the MBT. The MCT, MBT and MFT come close to each other in eastern parts. Barigad is the only fault that runs almost parallel to Himalayan arc between the MCT and MBT. Some of the transverse faults in this region are reported to be seismically active (Dasgupta et al., 1987).

The spatial pattern of earthquakes in central Nepal is shown in Figure 4. No major damaging event occurred in this region within Nepal but in the adjoining Tibet four events with $\mathrm{m}_{\mathrm{b}} \geq 6.0$ occurred. The events show a clustering pattern in east west trending segment of about $50 \mathrm{~km}$ wide (within $28^{\circ} \mathrm{N}$ and $29^{\circ} \mathrm{N}$ ). Up to $28^{\circ} \mathrm{N}$ the seismic activity is nearly devoid.

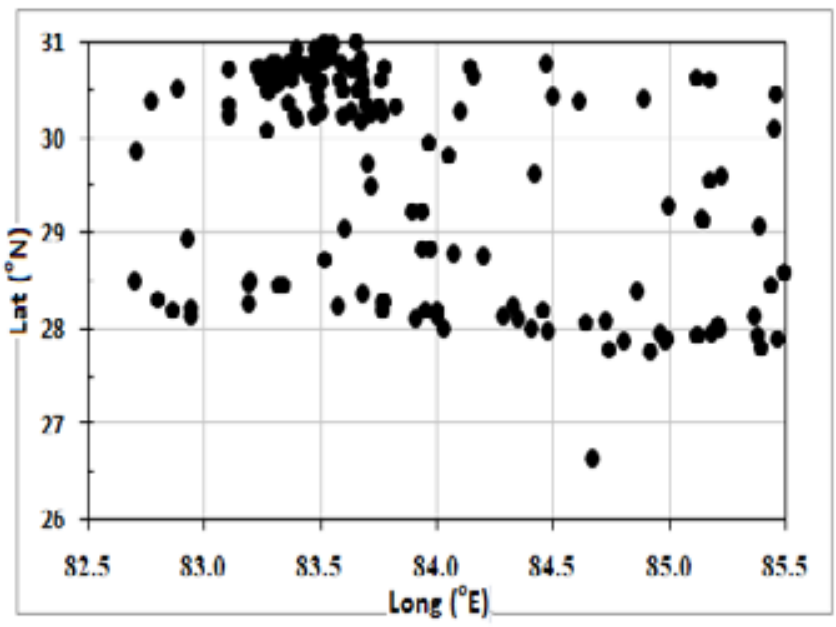

Figure 4: Spatial distribution of earthquakes in Central Nepal and its adjoining region

The region $\mathrm{C}$ comprises of easternmost part of the Nepal and its adjoining Tibet and Indian region (Fig. 5). This region is geologically complex as it is traversed by criss-cross pattern of transverse faults and lineaments. The trend of the lineaments is almost parallel to each other and follows approximately in the northwest-southeast direction. Normal faults with graben structures are prevalent in the adjoining 
Tibet region which trend mostly in the north-south direction. The region has been the site of one of the great earthquakes of the Himalayan thrust which occurred in 1934 caused widespread devastation in the adjoining Bihar state of India and the Central Nepal in and around Kathmandu valley.

From 1964 onwards, four medium size earthquakes with $m_{b} \geq 6$ have occurred of which are close to the Himalayan major thrusts. The region contributes about $45 \%$ seismic activity as compared to the total activity of the whole area considered in the present study. The 21 August 1988 earthquake $\left(\mathrm{m}_{\mathrm{b}}\right.$ 6.6) occurred in the epicentral tract of 1934 great earthquake barely at a distance of $30 \mathrm{~km}$ to its north. The damage pattern caused by this earthquake is similar to that of 1934 great earthquake but in a limited aerial extent. Further, it is interesting to note that the recent seismicity in this region propagates towards north up to the ITS between $86^{\circ}$ to $88.5^{\circ}$ E. The cluster of events occurs mainly in a small region $\left(30^{\circ} \mathrm{N}, 88^{\circ} \mathrm{E}\right)$ along northeast- southwest (Fig. $5)$. It is supposed that such activity might have been caused by the existing transverse and the normal faults, and more so by the complex local geological set up of the region. Activity is comparatively low to the north of $29^{\circ} \mathrm{N}$ for next nearly $100 \mathrm{~km}$.

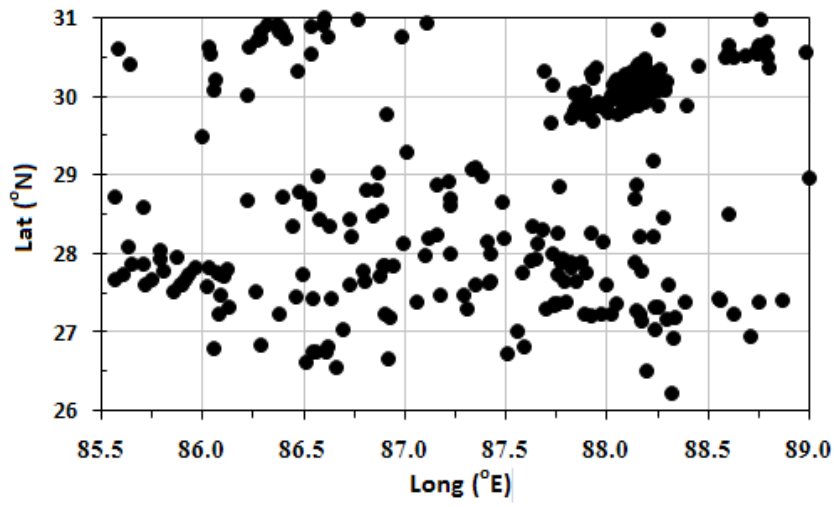

Figure 5: Spatial distribution of earthquakes in Eastern Nepal and its adjoining region from 1964 to $2008\left(\mathrm{~m}_{\mathrm{b}} \geq 4.1\right)$.

\section{CONCLUSIONS}

Nepal and its adjoining region in the Central Himalaya represent a seismically complex region which has been segmented into three regions, based on the seismic activity. An earthquake catalogue is prepared for the period 1964-2008 from NEIC and other data files. The data is found complete for the $\mathrm{m}_{\mathrm{b}} \geq 4.1$ with $\mathrm{b}$ - value 1.05 . Hence the complete part of the catalog is used to study the recent seismic activity in the region. For each region spatial distribution of earthquakes is studied and analyzed. A non- uniform distribution of earthquakes with certain segments having intense seismic activity in thrust zone of Central Himalaya signifies complex geologic and tectonic setting. The recent seismic activities are mainly due to the shallow focus events. In the recent time, the eastern parts of the Central Himalaya region is the most active with high but scattered seismic activity, whereas in the western portion, it is concentrated between the MCT and the MBT. In these two regions, intermediate events also occur frequently. However, comparatively very low seismic activity exists in the Central Nepal.

\section{REFERENCES}

1. Chandra, U. 1978. Seismicity, Earthquake mechanism and tectonics along the Himalayan range and vicinity.Physics Earth and Planetery Interior 16: 109-131.

2. Dasgupta, S., M. Mukhopadhaya, and D. R. Nandy. 1987. Active transverse features of the central portion of the Himalaya. Tectonophysics 136: $255-264$.

3. Gutenberg, B. and C. F. Richter. 1954. Seismicity of the Earth and Associated Phenomena.Hafner Pub. Pages.

4. Oldham, T. 1882. Catalog of Indian earthquakes, Mem. Geol. Surv. India, 19, 163-215. 5. Wyss, M. 2005. Human losses expected in Himalayan earthquakes. Natural Hazards 34: 305-314. 